
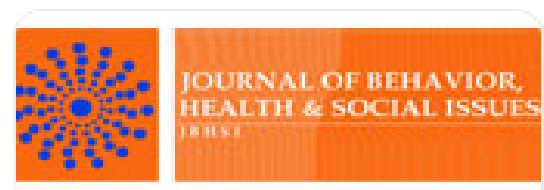

Journal of Behavior, Health \& Social Issues

ISSN: 2007-0780

jcpedro@unam.mx

Asociación Mexicana de Comportamiento y

Salud, A. C.

México

García-Cadena, Cirilo Humberto; Moral de la Rubia, José; Díaz-Díaz, Héctor Luis; Martínez-

Rodríguez, Juan; Sánchez-Reyes, Lorenzo; López-Rosales, Fuensanta

EFFECT OF FAMILY STRENGTH OVER THE PSYCHOLOGICAL WELL-BEING AND INTERNAL LOCUS OF CONTROL

Journal of Behavior, Health \& Social Issues, vol. 5, núm. 2, noviembre-abril, 2013, pp. 33-46

Asociación Mexicana de Comportamiento y Salud, A. C.

Distrito Federal, México

Available in: http://www.redalyc.org/articulo.oa?id=282228907003

How to cite

Complete issue

- More information about this article

Journal's homepage in redalyc.org

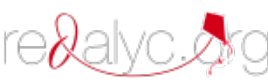

Scientific Information System 


\title{
EFFECT OF FAMILY STRENGTH OVER THE PSYCHOLOGICAL WELL-BEING AND INTERNAL LOCUS OF CONTROL
}

\author{
EFECTO DE LA FORTALEZA FAMILIAR SOBRE EL BIENESTAR \\ PSICOLOGGICO Y EL LOCUS DE CONTROL INTERNO
}

\author{
Cirilo Humberto García-Cadena* \\ José Moral de la Rubia* \\ Héctor Luis Díaz-Díaz** \\ Juan Martínez-Rodríguez* \\ Lorenzo Sánchez-Reyes * \\ Fuensanta López-Rosales* \\ * Facultad de Psicología. Universidad Autónoma de \\ Nuevo León (UANL), Monterrey, N.L., México. \\ ** The University of Texas-Pan American, Texas, \\ EE.UU.
}

\begin{abstract}
Received: December 7, 2012
Revised: February 1, 2013

Accepted: March 10, 2013

Authors contributed to the paper in the following way; CHGCtheoretical integration and application of structural equation modeling; JMR - data analysis; HLDD- technical translation from Spanish to English; JMR- tables and figures; LSR- search and synthesis of scientific articles; FLR- discussion.

All correspondence should be directed to: Cirilo Humberto García Cadena, PhD. Facultad de Psicología, UANL, Dr. Carlos Canseco 110, Mitras-Centro, CP. 64460, Monterrey, N. L., México. e-mail: ciriloenatoragmail.com
\end{abstract}

Abstract

If the development of the concept of "self" as a unit distinct from the environment ontogenetically follows the development of the concept of "us", then psychosocial constructs would play a very important role in explaining psychological constructs. The current study explores to what extent the psychosocial construct "family strength" can be used to predict the psychological constructs "psychological well-being" and "internal locus of control". Three different scales were administered to a non-probability sample of 400 subjects (153 males and 247 females) to measure family strength, psychological well-being and internal locus of control. Structural Equation Models found that $67 \%$ of the variance in psychological well-being and $59 \%$ of the variance in internal locus of control were predicted by "family commitment-trust" with good data adjustment $(\chi 2 / \mathrm{df}=1.78, \mathrm{GFI}=.95, \mathrm{AGFI}=.94$, and $\mathrm{NFI}=.92$ ). These findings show the primacy of the psychosocial dimension over the psychological dimension. The article discusses the implications of these findings for professional healthcare practice. Key words: Family strength, psychological well-being, and internal locus of control. 


\section{Resumen}

Si la adquisición del concepto de sí mismo como unicidad diferenciada del mundo es ontogenéticamente posterior a la adquisición del concepto de "nosotros", los constructos psicosociales tendrían un importante peso explicativo sobre los constructos psicológicos. La presente investigación tiene como objetivo estudiar el peso explicativo del constructo psicosocial fortaleza familiar sobre los constructos psicológicos bienestar psicológico y locus de control interno. Tres escalas de fortaleza familiar, bienestar psicológico y locus de control y un cuestionario socio-demográfico fueron aplicados a una muestra no probabilística de 400 participantes de población general (153 hombres y 247 mujeres). Se halló mediante modelamiento de ecuaciones estructurales que $67 \%$ de la varianza del bienestar psicológico y $59 \%$ de la varianza de locus de control interno eran predichas por compromiso-confianza familiar con buen ajuste a los datos $(\chi 2 / \mathrm{gl}=1.78, \mathrm{GFI}=.95, \mathrm{AGFI}=.94$ y NFI = .92). Así lo psicosocial mostró un peso significativo sobre lo psicológico. Se discuten las implicaciones de los hallazgos para la práctica de los profesionales de la salud.

Palabras clave: Fortaleza familiar, bienestar psicológico, y locus de control interno.

\section{Introduction}

Studies suggest that the development of the concept of "self" ontogenetically follows the development of the primigenic diffused and undifferentiated concept of "us", in which we see ourselves as one and the same with our environment (Rochat, 2009). Our individual identity and concept of "self" as an entity distinct from each other and the environment seems to stem from a collective cognitive structure that gives birth and sustains our psychological development. This could help explain how psychosocial constructs may help explain psychological constructs. This proposition is supported by García and Corral (2010). These authors found that social identity was able to predict $60 \%$ of the variance in internal locus of control among residents of the southern part of the state of Nuevo León, México. Similarly, Moral, González and Ortega (2009) found that "ideological identity" as a psychosocial construct predicted $23 \%$ of the variance while selecting political parties or candidates (individual behavior).

This article is based on Kantor \& Smith's field theory (1975). The theory views the psychological dimension of human functioning as including the adjustments or adaptation of the individual to environmental demands in general. The theory views the psychosocial dimension as including the adjustments or adaptation of the individual in response to social demands. The concept of "social interaction" included in the theory makes reference to the behavior of the individual in response to entities, groups we belong to, ideologies, norms and social representations (Gracia \& Musitu, 2000).

The current study views "family strength" or "family resilience" as a predictor or independent variable given that as a social construct it is significantly associated with the psychological wellbeing of family members (Baumrind, 1989). This construct has been defined as the combination of behaviors and functional competencies the family exhibits during moments of great distress or adverse circumstances. These in turn determine the family's ability to recover and maintain its collective integrity while promoting the wellbeing of each family member and the family as a whole (McCubbin, McCubbin \& Thompson, 1994). Indicators of "family strength" or "family resilience" include: open communication, mutual support, interest in other family members, time spent together, spirituality and prosocial values (Orthner, Jones-Sanpei, \& Williamson, 2004).

It seems pertinent to define the concepts of "physical well-being", "subjective well-being" and "psychological well-being" given that psychological well-being is one of the main concepts in this study. When someone says that he/she feels well, we usually understand that reference is being made to physical well-being. The implication of this statement is that there is no pain resulting 
from any known or unknown illness. The person is using himself or herself as a point of reference and on that basis judges his/her health as being adequate. This self-assessment is obviously the result of a subjective view of physical well-being even though this is not explicitly stated. The available scientific literature makes reference to people's subjective well-being (Palomar, 2004; Zubieta, Muratori, \& Fernández, 2012) and psychological well-being (Bermúdez, Álvarez \& Sánchez, 2003; Sánchez, 1998) while clearly differentiating both. Usually, when we make reference to subjective well-being, we make reference to emotions and life satisfaction (Hedonic Approach). We in turn use the concept of psychological well-being to refer to cognitive processes. An example of this would be our determination of whether or not we have reached self-actualization (Blanco \& Díaz, 2005). The inter-behavioral approach however critics this distinction between subjective and psychological well-being given that in its view it lacks theoretical support. This approach proposes that a person's global well-being includes the physical, psychological and social health and that well-being in all of these dimensions could be subjective if evaluated by the individual himself/herself (see Díaz, Blanco \& Duran, 2011). If a person reports feeling physically well, he/she believes that he/she is adequately responding to all expectations, and as a result is satisfied with his/her life, we could say that this person is well or that he/she possesses "inter-behavioral efficacy" (Kantor, 1959). This global concept of well-being includes what Keyes (1998) calls "social well-being". This concept is also in harmony with recent approaches to positive mental health (Lamers, Westerhof, Bohlmeijer, ten-Klooster, \& Keyes, 2011) and the conceptualization of mental health of the World Health Organization (2004).

Internal locus of control is the other dependent construct in this study. It was selected on the basis that cultural collectivism promotes social identity and the adherence to group norms and goals, as opposed to individual identity, norms and goals. It has been proposed that collectivist cultures strengthen external locus of control while individualistic cultures promote internal locus of control (Triandis, 2001). The belief in an internal locus of control is associated with the idea that whatever happens to us is determined by our own behavior. Alternatively, we have an external locus of control if we believe that whatever happens to us is the result of forces beyond our control such as luck, destiny, fate, other more powerful people, or supernatural forces (Mirowsky \& Ross, 2012).

The objective of this study is to find out to what extent "family strength" can predict "psychological well-being" and "internal locus of control" in a sample of the general population. In other words, we want to find out if a psychosocial construct can predict two psychological constructs. A significantly large sample from the general population of Guadalupe, Nuevo Leon, Mexico was selected as it inevitably includes male and female subjects as well as subjects from a wide age range. This enabled us to validate our model for males, females, adolescents and adults.

Mexican culture has been described as a coIlectivist culture. This means that it values the social, corporate and/or group over the individual (Omar et al., 2007; Vargas, 2007). Other studies have already identified the Mexican and other Latin American cultures as giving primary importance to the family (Díaz-Guerrero, 2003). Based on this, we predicted that "family strength" would significantly explain or predict personal variables such as "degree of satisfaction with our own lives" and level of "self-efficacy" (internal locus of control). We predicted that our model would be valid for males and females as well as for different age groups.

\section{Methodology \\ Participants}

This study relies on a non-probability sample of convenience of 400 residents of the city of Guadalupe, Nuevo León, México. The sample is comprised by 247 females and 153 males. As part of our data analysis we decided not to include cases with missing values. This action brought the size of our sample from 400 to 334 . 208 or $62 \%$ of these are female and 126 or $38 \%$ are male. A binomial test shows that the number of females in the sample is significantly greater than the number of males (binomial test: $p<.01)$. The mean age is 33.83 years $(S D=17.58)$ and ages ranged from 10 to 85 years. Frequencies by age group included: 
100 participants or $(30 \%)$ in the 10 to 19 year age group (adolescents), 93 or (28\%) in the 20 to 39 year age group (young adults), 110 or (33\%) in the 40 to 59 year age group (mature adults), and 31 or $(9 \%)$ in the 60 or higher age group (older adults). The gender distribution showed differences by age groups $(\chi 2[3, \mathrm{~N}=334])=13.17, p<.01)$. There were more males than females in the 10-19 age group and more females than males in the 20 to 60 and older age group. The mean level of education was 9 years $(S D=3.61)$, with years of education ranging from 0 to 19 . No significant differences in levels of education were detected by gender $(t[317]=-1.55, p=.12)$. An analysis by occupation showed that 115 or (35\%) are housewives, 102 or $(31 \%)$ are students, 81 or $(25 \%)$ are salespersons or office workers, 16 or ( $5 \%$ ) are laborers, 8 or (3\%) are professionals and 4 or (1\%) are retired. The mean biweekly family income is $\$ 3,236$ Mexican pesos $(S D=\$ 2,534)$. Salaries ranged from $\$ 400$ to $\$ 20,000$ with a statistically equivalent mean income from males and females $(t[210]=-0.42, p=.68)$.

\section{Research Instruments}

A questionnaire was used to collect socio-demographic data including gender, age, level of education, occupation, and biweekly family income. A multiscale was also used to measure the three main constructs in our model. The McCubbin, McCubbin and Thompson scale (1991) was used to measure our independent variable "family strength". This is a Likert type scale that rates responses on a 4 point scale. It possesses high internal consistency (alfa $=.82$ ) and three factors: commitment-trust, challenge (helplessness-passivity) and external control-fatalism. The scale has 11 direct items related to the commitment-trust factor and 9 reverse items related to the helplessness-fatalism factor.

McCubbin et al. (1994) suggest that we should report total scores on this scale and view these scores as unidimensional given that its factor structure is not very stable varying from 1 to 4 factors by sample. To measure the "subjective well-being" dependent variable we used half of the scale to measure this construct developed by Treviño and García (2012) (alfa $=.87$ ). This 20 item scale was developed by combining 9 items from the Diener, Emmons, Larsen and Griffin Life Satisfaction Scale (1985), 4 items from the
Cummins, Eckesley, Pallent, Van-Vugt y Misajon Personal Well-Being Index (2003), and 7 items Ryff Psychological Well-Being Scale (Díaz et al., 2006). We opted for this shortened version of the scales as suggested by Treviño \& García (2012) given the scale's structure of two correlated factors, one with the ten even items and one with the ten uneven items. We decided to use the half of the scale with the uneven items because this one showed greater consistency.

We used the internal consistency factor of the Locus of Control Scale to measure our Internal Locus of Control variable (La Rosa, 1988). The complete scale of La Rosa (1988) has 53 Likert type items with a 5 point rating scale and five factors: 1) fatalism/luck with 14 items that evaluate beliefs in a disorganized world where life outcomes depend on factors such as destiny or luck $($ alpha $=.89) ; 2)$ powers of the macrocosm with 11 items that evaluate beliefs in an organized world in which life outcomes depend on people with power not closely related to the individual (alpha $=.87$ ); 3) affectivity with 9 items that evaluate goal attainment thanks to affective relationships the individual maintains with those around him/her (alpha $=.83) ; 4)$ internal instrumentality with 10 items that evaluate situations in which the individual controls his/her life through his own efforts, work and capacities (alpha $=.82$ ); and 5) powers of the microcosm with 9 items that evaluate beliefs in an organized world in which we depend on powerful people close to us (alpha $=.78$ ). As a result, we have an instrument with four factors and 43 items that measure external locus of control, one factor and ten items that measure internal locus of control. We opted for this last factor and scale due to its high internal consistency and greater convergent validity and given that it includes measures for self-concept, self-esteem, and negative affectivity (La Rosa, 1988). These 40 items were randomly distributed in the scale along with 22 items from other scales not used in this study.

\section{Study Design and Research Procedures}

This is an ex post facto, correlational, cross sectional survey study. Data were collected by undergraduate psychology students after they were trained for this purpose. Students who collected the data were compensated with funds from the 
System for Complete Family Development of the State of Nuevo León, México. Student surveyors made home visits to complete the survey interviews. They informed potential participants about the nature and objectives of the study and promised them anonymity before requesting their informed consent to participate in the study. Surveyors requested to interview one person per household. All these procedures were followed to comply with the ethical standards of the Mexican Psychological Association (2007). A significantly large number of communities were included in the study in an effort to increase the representativeness of the sample.

\section{Data Analysis}

Two structural analyzes were conducted with three latent variables. Previously, a confirmatory factor analysis was conducted to contrast a unidimensional measurement model for each of the three latent variables. The adjustment of the two structural equation models included an estimate for the full sample (one group) as well as differential adjustment by gender for three age groups. Only the findings of the models without restrictions were reported.

In every case, discrepancies were calculated based on scale-free least squares method given the strong deviation of multivariate norms (Coefficient of Mardias Multivariate Curtosis $>70$ ). To contrast the significance of the parameters we relied on the Bootstrap method (for scale-free least squares) with a $95 \%$ confidence interval and 1,000 random samples. Seven indexes were used to measure Goodness of Fit: the Coefficient of the Chi Square and its degrees of freedom $(\chi 2 /$ df), the GFI Goodness of Fit Index of JöreskogSörbom and its revised version (AGFI), the index for normal adjustment, the relative adjustment Index of Bollen (RFI) and the non-standardized mean square residuals (RMS). We identified the following adjustment values as good: $\chi 2 / \mathrm{df} \leq 2$, $\mathrm{GFI} \geq .95$, AGFI, NFI y RFI $\geq .90$; and the following as adequate: $\chi 2 / \mathrm{df} \leq 3$, GFI $\geq .85$, AGFI, NFI y RFI $\geq .80$ (Kline, 2010). The RMS value closest to a saturated model (0) and farthest from the value of the independent model is indicative of the best adjustment. The Goodness of Fit between the two models was calculated by the difference of the Chi Squares. The internal consistency of the model for each construct was estimated by Chronbach Alpha Coefficients. We considered a Chronbach Alpha equal or greater than .70 as high, Chronbach Alphas higher than .60 but lower than .70 as adequate, and Chronbach Alphas lower than .60 as low (Cronbach \& Shavelson, 2004). These statistical tests were conducted with the AMOS 18 program.

\section{Findings}

\section{Contrast of models of unidimensional measures for the constructs}

We contrasted a unidimensional measurement model with 20 indicators for the "family strength" latent variable. The parameters were found to be significant, except for the coefficient for item 6 of the multi-scale (In my family problems are the result of the errors we make) $(\beta<-.01 ; \mathrm{B}=-0.02$; IC 95\%: $-0.48,0.57 ; p=.94)$. Consequently, we deleted this item. All parameters were found to be significant in the new 19 items model. Each of the items in the model accounted for 3 to 45 per cent of the variance, with a mean variance of 23 (Figure 1).

The data adjustment was adequate in general: $\chi 2 /$ $\mathrm{df}=485.84 / 152=3.20, \mathrm{GFI}=.93, \mathrm{AGFI}=.91, \mathrm{NFI}$ $=.86, \mathrm{RFI}=.85$ y $\mathrm{RMR}=0.07$ (0.14 for the independent model). The internal consistency of the 20 items was high $(\alpha=.80)$ and it went up to .81 after deleting item 6 .

We were not able to reproduce the solutions of 3 or 4 expected factors by exploratory factor analysis with different factor extraction and rotation methods. We were able however to reproduce two correlated factors. The number of factors could be justified using Cattell's criterion (inflection point of the sedimentation curve of the correlation matrix values).

Through an analysis of the key components and oblimin rotation we defined the first factor "commitment-trust" with the 11 direct items $(\alpha=$ .83 ) and the second factor "helplessness-fatalism" with the 9 reverse items $(\alpha=.72)$. Reverse item 6 of the second factor in the multi-scale (In my family problems are the result of our own mistakes) showed a low saturation level $(<.30)$. It's deletion increased the factor's internal consistency 


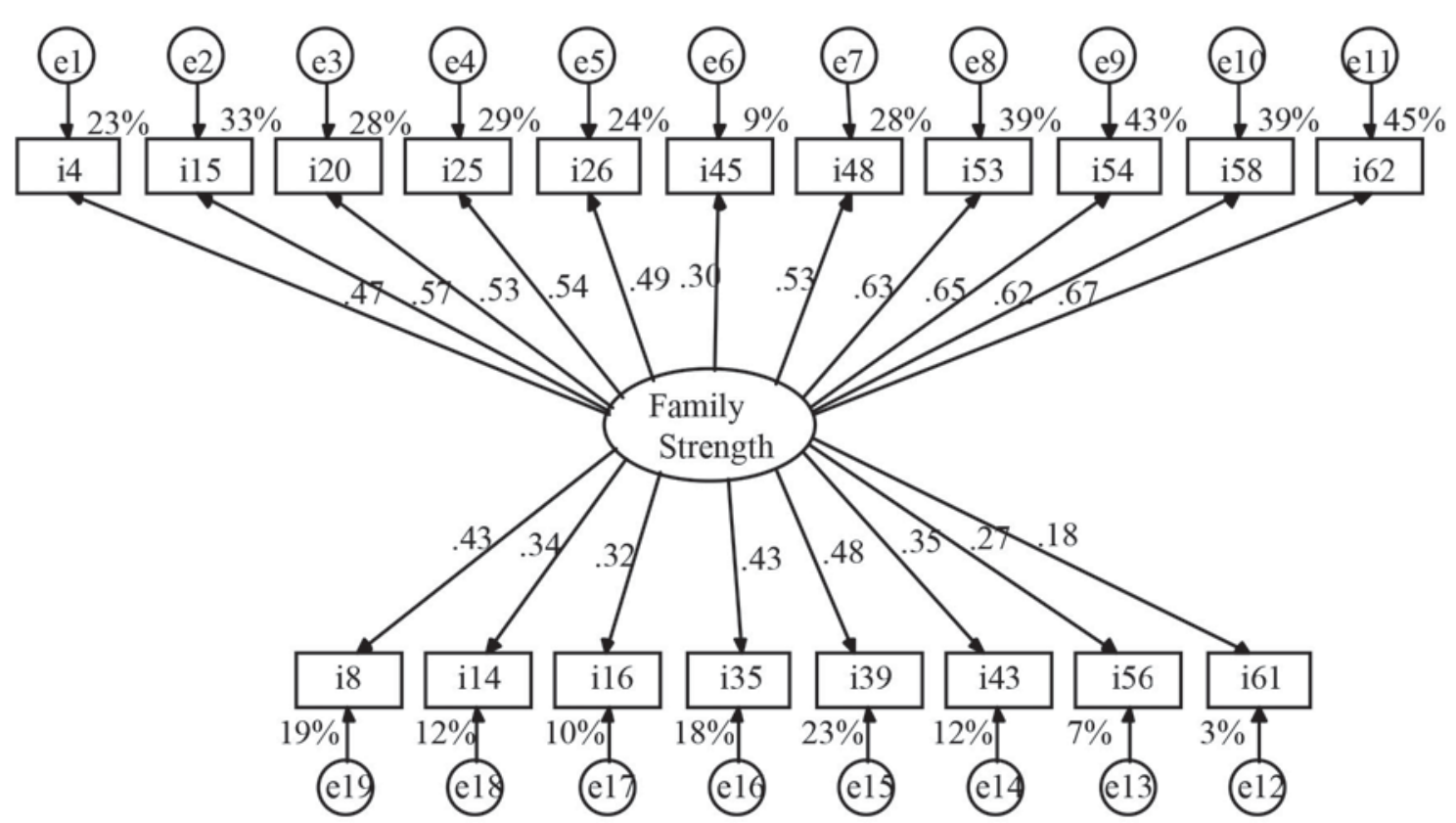

Figure 1. Unidimensional standardized model with 19 Indicators of Family Strength estimated by scale-free least squares.

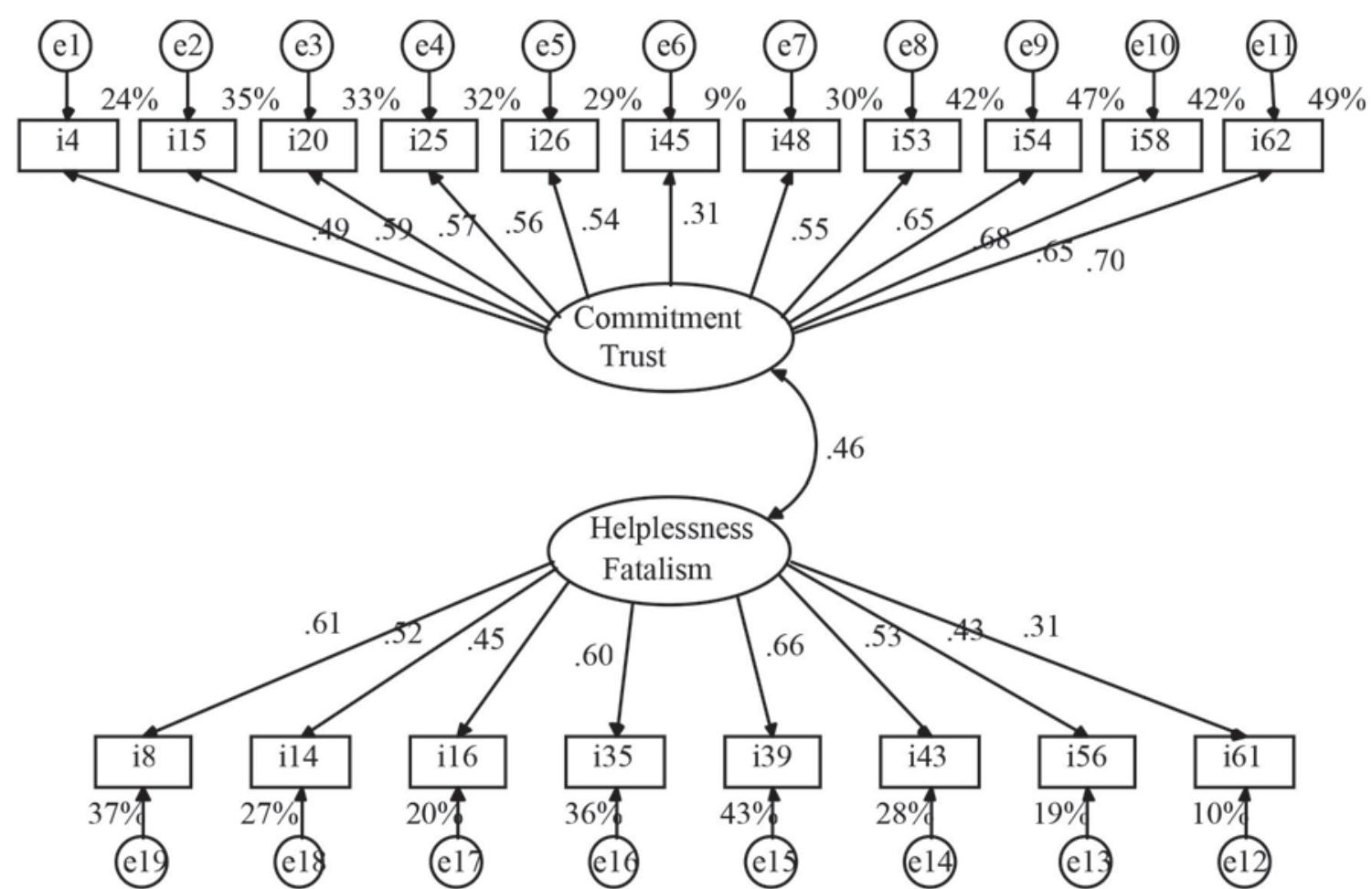

Figure 2. Standardized model of two correlated factors for Family Strength estimated by scale-free least squares. 
to $(\alpha=.74)$. Once again, item 6 did not show a significant coefficient as part of a confirmatory factor analysis when utilizing the model of two correlated factors ( $\beta=.07 ; \mathrm{B}=0.19$; IC 95\%: -0.29 , $0.57 ; p=.41)$. As a result, this item was deleted. All the parameters for the 19 items model were found to be significant. Each of the 19 items accounted for 10 to 49 percent of the variance with a mean variance per item of 32 . There was a moderate positive correlation between the two factors $(r=$ $.46, p<.01$ ) (Figure 2). The data adjustment was good: $\chi 2 / \mathrm{df}=183.69 / 151=1.22, \mathrm{GFI}=.97, \mathrm{AGFI}=$ $.97, \mathrm{NFI}=.95, \mathrm{RFI}=.94$ y $\mathrm{RMR}=0.04$ (0.14 for the independent model). The Goodness of Fit was definitely better than that of the unidimensional model: $\Delta \chi 2(1, \mathrm{~N}=334)=302.15, p<.01$.

Structural equation models involving the three or four predicted factors identified at least one very high correlation (>.80). This suggests forced separations of the collective variance. On the other hand, the distinction between two factors seems justified by their moderate correlation. We must highlight that the definition of two factors with direct and reverse items is usually indicative of conceptual unity. This is because they reveal differential response patterns of agreement or disagreement. Such responses are usually influenced by social desirability or congruence with the same concepts (Müller, Sokol, \& Overton, 1999).

A unidimensional model of "family commitmenttrust" involving 11 indicators consistent with this family trait, found all parameters to be significant.
Each of the items accounted for 9 to 48 percent of the variance with a mean percentage of 34 (Figure $3)$. The data adjustment was good: $\chi 2 / \mathrm{df}=57.33 / 44$ $=1.30, \mathrm{GFI}=.99, \mathrm{AGFI}=.98, \mathrm{NFI}=.97, \mathrm{RFI}=.97$ y $R M R=0.02$ (0.11 for the independent model), and with a Goodness of Fit that was significantly higher than the two previous ones.

Hence, the Family Strength Scale can be reduced to its factor of direct items. We compared a two factor model (Family Strength) in an effort to provide support to our previous statement. The standardized coefficient for determining "commitment-trust" by "family strength" was very high $(\beta=.80)$, and explained $65 \%$ of the variance. At the same time, the coefficient for "helplessnessfatalism" was moderate $(\beta=.58)$ and accounted for $33 \%$ of the variance. The adjustment indexes for this model totally coincided with the two correlated factors model and the percentage of variance accounted for by the items. All this strongly suggests that "commitment-trust" with good data adjustment within this model is basically indicative of "family strength".

We developed a unidimensional model for psychological well-being with 10 indicators. All parameters were found to be significant. Each of the 10 items was able to account for or predict from 10 to 40 percent of the variance with a mean of 28 percent (Figure 4). The indexes for data adjustment were good: $\chi 2 / \mathrm{df}=67.88 / 35=$ $1.94, \mathrm{GFI}=.98, \mathrm{AGFI}=.96, \mathrm{NFI}=.95, \mathrm{RFI}=.93$ and $\mathrm{RMR}=0.05$ ( 0.24 for the independent model). The

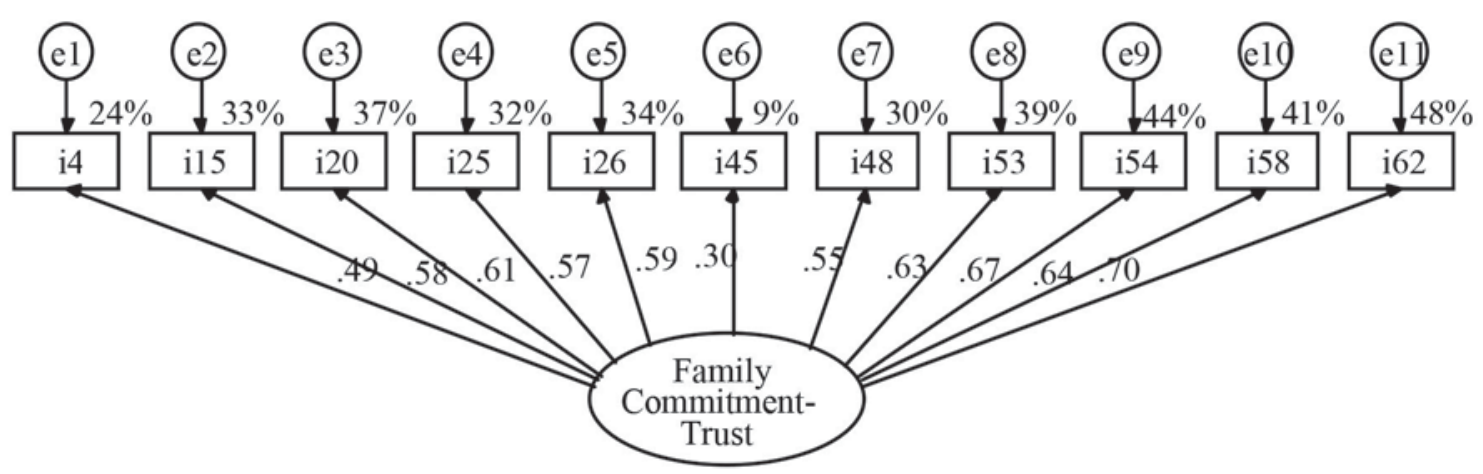

Figure 3. Unidimensional standardized model with eleven indicators of Family CommitmentTrust estimated by scale-free least squares. 


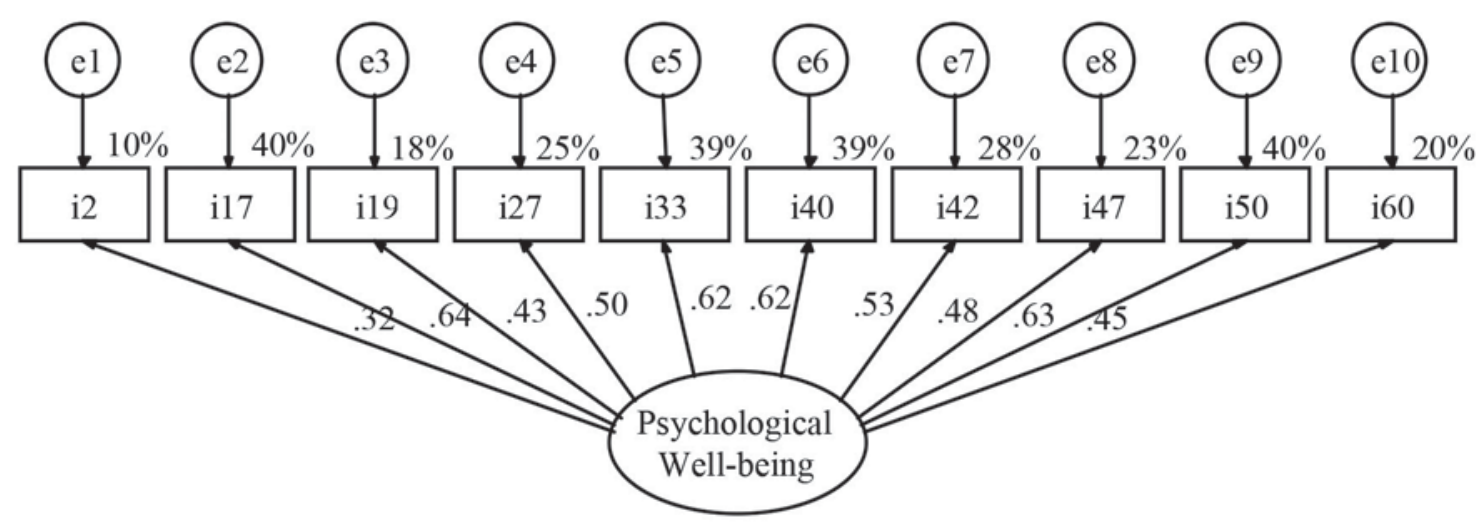

Figure 4. Unidimensional standardized model for Psychological Well-Being with 10 indicators estimated by scale-free least squares.

internal consistency of the 10 items was high $(\alpha$ $=.79$ ). This level of internal consistency was not increased by the deletion of any item.

A unidimensional model with 10 indicators was also developed to predict internal locus of control. All parameters were found to be significant. Each of the items accounted for or predicted from 10 to 56 percent of the variance with a mean percentage of 30 . The indexes for data adjustment were good: $\chi 2 / \mathrm{df}=70.85 / 35=2.02, \mathrm{GFI}=.98, \mathrm{AGFI}$ $=.96, \mathrm{NFI}=.95, \mathrm{RFI}=.94$ y $\mathrm{RMR}=0.03(0.13$ for the independent model) (Figure 5). The internal consistency of the 10 items was high $(\alpha=.79)$ and it was not increased by the deletion of any item.

\section{Contrast of the Regression Structural Model}

A structural model was developed where "psychological well-being" and "internal locus of control" (endogenous variables) were predicted by "family commitment-trust" (exogenous variable). These three variables were treated as latent variables. In the structural model the exogenous variable comprised 11 indicators while each of the two endogenous variables comprised 10 indicators. All the parameters were found to be significant. Each of the 31 items and two endogenous variables accounted for or predicted from 8 to 67 percent of the variance with a mean percent of 32 . The indexes for data adjustment were good: $\chi 2 / \mathrm{df}=$

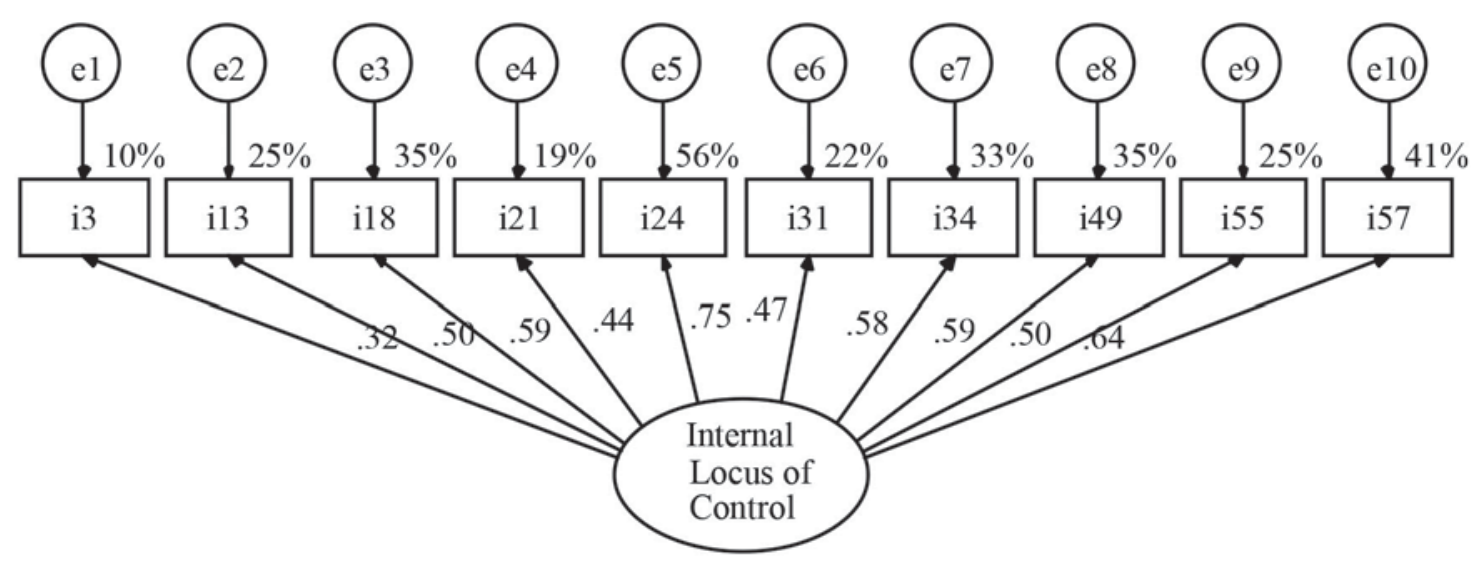

Figure 5. Unidimensional standardized model with 10 Indicators to predict Internal Locus of Control estimated by scale-free least squares. 


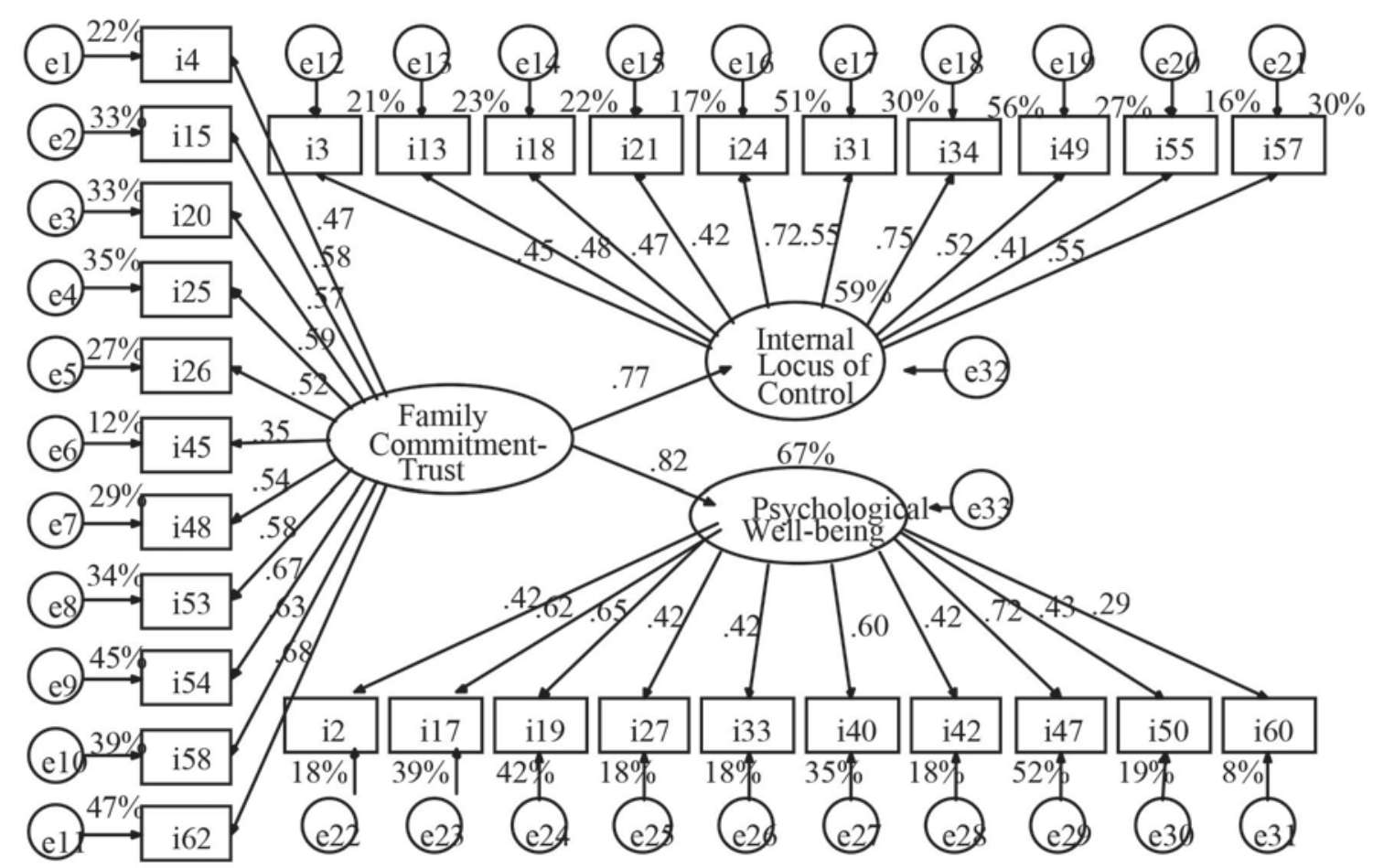

Figure 6. Standardized model for Psychological Well-Being and Internal Locus of Control as predicted by Family Commitment-Trust estimated by scale-free least squares in the total sample.

$770.65 / 432=1.78, \mathrm{GFI}=.95, \mathrm{AGFI}=.94, \mathrm{NFI}=.92$, $\mathrm{RFI}=.92$ and $\mathrm{RMR}=0.05$ ( 0.13 for the independent model). Family "commitment-trust" accounted for $67 \%$ of the variance in "psychological well-being" and for $59 \%$ of the variance in "Internal Locus of Control" (Figure 6).

A multi-group analysis of this model involving males and females without restrictions found all parameters to be significant for both samples. It also found the adjustment indexes to be from $\operatorname{good}(\chi 2 / \mathrm{df}=1124.16 / 864=1.30, \mathrm{AGFI}=.92, \mathrm{NFI}$ $=.90$ and $\mathrm{RMR}=0.05)$ to adequate $(\mathrm{GFI}=.93$ and RFI = .89). "Family commitment-trust" accounted for $64 \%$ of the psychological well-being among females and $74 \%$ of the psychological well-being among males. A multi-group analysis of this model without restrictions by age groups found most parameters to be significant for adolescents, young adults and mature adults. The only non-significant items were item 42 (I am dissatisfied with my life), which is related to the psychological well-being of adolescents, and item 18 (Success in employment depends on me), and item 21 (Whatever happens to me depends on me), which is related to the Internal Locus of Control of young adults. The data adjustment indexes went from good $(\chi 2 / \mathrm{df}$ $=1385.70 / 1296=1.07, \mathrm{AGFI}=.90$ and $\mathrm{RMR}=0.06$ ) to adequate $(\mathrm{GFI}=.91, \mathrm{NFI}=.88$ and $\mathrm{RFI}=.89)$. Family commitment-trust accounted for $70 \%$ of the psychological well-being of adolescents, $67 \%$ of the psychological well-being of young adults and $74 \%$ of the well-being of mature adults. At the same time, this factor accounted for $64 \%$ of the Internal Locus of Control of adolescents, $54 \%$ of that of young adults and $70 \%$ of that of mature adults. The size of the three age groups was statistically equivalent $(\chi 2[2, \mathrm{~N}=303]=1.45, p=$ .49). Older adults were excluded from the sample given the small number of this subgroup $(n=31)$.

The data adjustment indexes were found to be adequate in a model with the "Family Strength" exogenous latent variable (with 19 indicators) for 
the total sample (one group): $\chi 2 / \mathrm{df}=1719.41 / 700$ $=2.46, \mathrm{GFI}=.92, \mathrm{AGFI}=.91, \mathrm{NFI}=.87, \mathrm{RFI}=.87$ and $\mathrm{RMR}=0.06$ ( 0.15 for the independent model). Its Goodness of Fit was worse than that of the previous model with "family commitment-trust": $\Delta \chi 2(268, \mathrm{~N}=334)=948.76, p<.01$. Furthermore, this model accounted for a greater percentage of the variance in Psychological Well-being (83\%) while it accounted for a lower percentage of the variance in Internal Locus of Control (51\%) (Figure 7).

The analysis of a second model without restrictions to include the male and female groups found most parameters to be significant for both groups. Only indicators 61 (In my family it is better to stay home than to go out to socialize with others), as related to family strength among females ( $\mathrm{s}=.10 ; \mathrm{B}=0.35$, IC 95\%: $-0.10,1.06 ; p$ $=.12$ ). The data adjustment indexes went from $\operatorname{good}(\chi 2 / \mathrm{gl}=2279.66 / 1400=1.11$ and $\mathrm{RMR}=0.07)$ to adequate $(\mathrm{AGFI}=.89, \mathrm{GFI}=.88, \mathrm{NFI}=.85$ and $\mathrm{RFI}=.84)$. The model accounted for $89 \%$ of the variance in psychological well-being for females and $95 \%$ of that of males. It also accounted for $71 \%$ of the variance in Internal Locus of Control

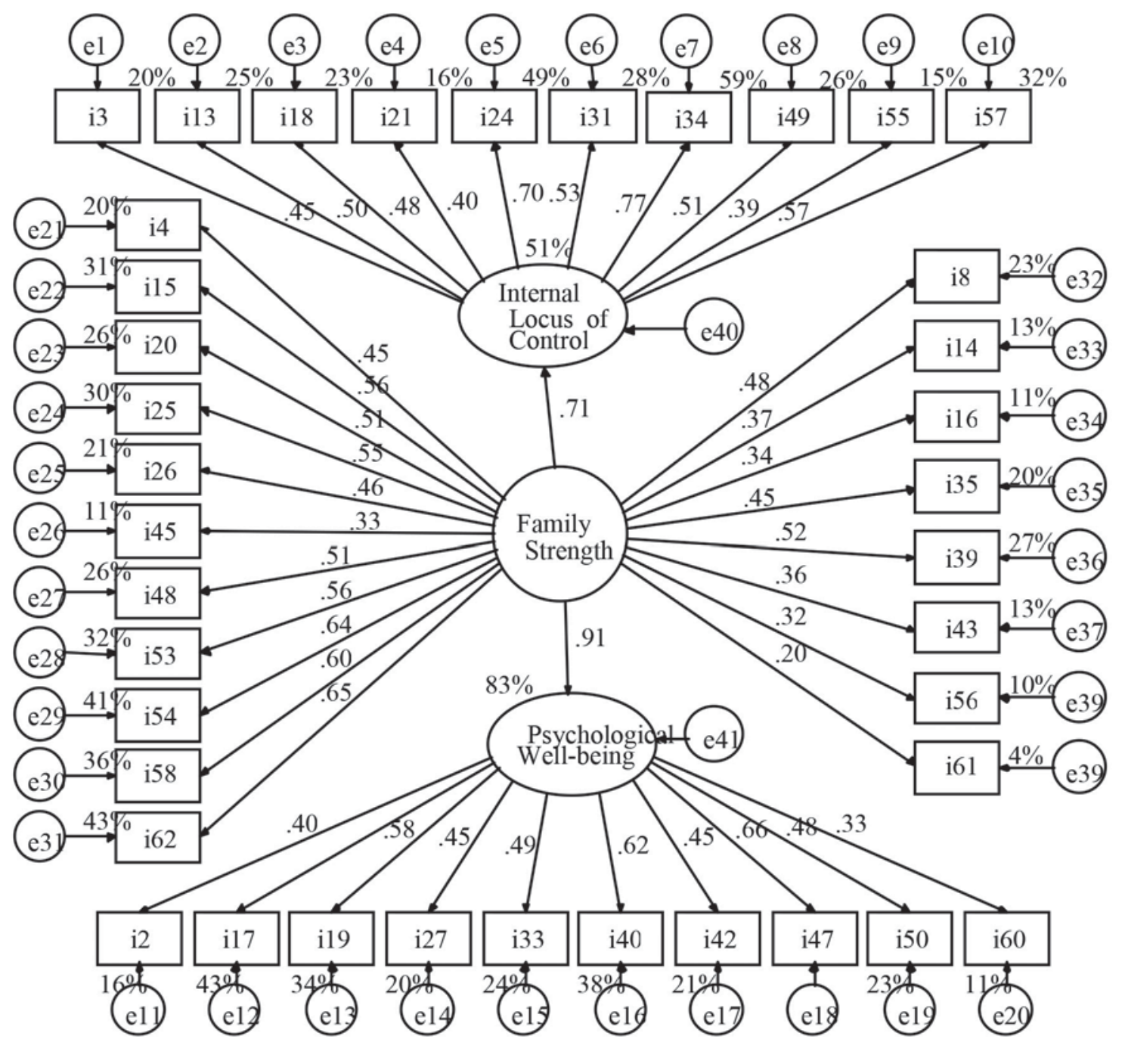

Figure 7. Standardized model for Psychological Well-Being and Internal Locus of Control as predicted by Family Strength estimated by scale-free least squares in the total sample. 
for females and $77 \%$ of the variance for males. The data adjustment was worse than that of the first model for different age groups by gender: $\Delta \chi 2(536, \mathrm{~N}=334)=1155.50, p<.01$.

The multi-group analysis of the second model without restrictions found most parameters to be significant for adolescents, young adults and mature adults. The only items lacking predictive significance were: item 42 (I am dissatisfied with my life), item 21 (Whatever happens to me depends on me), item 55 (Having enough money depends on me) as related to the Internal Locus of Control for young adults. Item 62 also lacked predictive significance as related to Family Strength for mature adults. The data adjustment indexes went from good $(\chi 2 / \mathrm{df}=2538.56 / 2100=1.21 \mathrm{y}$ $\mathrm{RMR}=0.07)$ to adequate $(\mathrm{GFI}=.88, \mathrm{AGFI}=.87$, $\mathrm{NFI}=.84$ and $\mathrm{RFI}=.83$ ). The model accounted for $83 \%$ of the variance in psychological well-being for adolescents and young adults and for $87 \%$ of the variance in psychological well-being among mature adults. The model also accounted for $54 \%$ of the variance in Internal Locus of Control for adolescents, $45 \%$ of the variance among young adults and $65 \%$ among mature adults. The data adjustment was worse than that of the first model that focused on various groups by age groups: $\Delta \chi 2(804, \mathrm{~N}=303)=1152.86, p<.01$.

\section{Discussion}

Many studies have focused on family characteristics and their importance for the psychological well-being of its members (Baumrind, 1989; Duke, Lazarus, \& Fivush, 2008; Leary, Kelley, Morrow, \& Mikulka, 2008; Palomar \& Cienfuegos, 2007; Pettit, Bates, \& Dodge, 1997). Most studies however only report correlations and differences in means among key variables. Very few studies rely on sophisticated multivariate models that can enable us to infer the influence of certain variables over others, such as the structural equation modeling used in this study.

As expected, Family Strength predicted Internal Locus of Control and the degree of people's satisfaction with their lives. Our models were able to account for moderate to high levels of the variance in the dependent variables. These outcomes had been hypothesized based on the premise that Mexican culture is collectivistic in nature and as a result, it favors the group over the individual (Omar et al., 2007; Vargas, 2007). Secondly, in the Mexican and other Latin American cultures the family is the main social nucleus (Díaz-Guerrero, 2003). Consequently, family wellbeing is a prerequisite for the well-being and the perceptions of success of family members. The association between these two variables has good data adjustment and seems valid for both males and females and for different age groups. It also highlights the importance of the psychosocial over the psychological.

García and Corral (2010) reported that social identity greatly influences Internal Locus of Control. This suggests that the extent to which someone identifies himself/herself as a member of a broad social group, the extent to which the person is happy with him/herself, and the extent to which the person positively values his/her group membership, will be associated with the belief that whatever happens in his/her life depends mostly on himself/herself. Furthermore, whatever happens within the family seems to be directly associated with the person's level of satisfaction with his/her life and his/her ability to achieve life goals. Su and Li (2002) studied a large sample of adolescents in the United States of America and found that those coming out of intact and functional families had a mean level of psychological wellbeing higher than the level of adolescents coming from families undergoing separation or divorce. We could hypothesize that family identity as an independent variable will predict psychological well-being. Family disintegration has a devastating impact on the lives of individuals given that they usually spend their formative years being part of their respective families. These facts seem to support the idea that the concept of "we" or "us" precedes the emergence of the concept of "self" (Rochat, 2009).

The previous statements are in harmony with various studies supporting the notion that the family unit is of vital importance for Mexicans (Díaz-Guerrero, 1982; Holtzman, Díaz-Guerrero \& Swartz, 1975; La Rosa, 1986). Such studies strongly suggest that individual well-being and the perception of success are directly dependent on the strength of our respective families of origin. 
Level of commitment and trust among family members as they face problems are two of the main indicators of such family strength.

These findings have several implications for psychologists and other human service professionals. We should focus on building and strengthening families if the goal of our intervention is to enhance the psychological well-being of those who seek our help. We should particularly concentrate our efforts in strengthening the commitment of family members to the family unit and on trying to cultivate mutual trust. Systemic family therapy could help us accomplish these goals as it seeks to strengthen family bonds, to increase family resilience and to facilitate the effective handling of stressors (Montalvo, 2009). This intervention approach should be effective for males, females, adolescents and adults.

One of the limitations of this study is that it relied on a non-probability sample. Consequently, study findings cannot be generalized to the larger population of the city of Guadalupe, Nuevo León, México or any other population. The findings of this study simply provide insights that could be further tested in future more rigorous studies. The study design represents another limitation. The ex post facto, cross sectional nature of the study is far from an experimental design and for this reason does not enable us to establish cause and effect relationships among variables. We would need experimental or longitudinal studies in order to accomplish that.

Our initial study sample was reduced by $16.5 \%$ as a result of our decision to exclude from the study cases with missing values. Nevertheless, the use of the bootstrap technique enabled us to significantly increase the power of our data analysis to .80 or higher in our different models given that all of them had fewer than 35 degrees of freedom (Kim, 2005). We wish to emphasize that our research instruments were reviewed and revised to make them valid for a general population with a very wide age range going from adolescents to older adults. The use of instruments for particular age groups would have greatly complicated the task of making inter group comparisons. The scale developed to measure Family Strength was also intended for use with persons from a wide age range
(McCubbin et al., 1994). Similarly, the scale to measure Locus of Control is valid for use with adolescents and adults (La Rosa, 1988).

We conclude that family strength, and particularly family commitment and trust as family members seek to overcome problems significantly contribute to the psychological well-being of family members and to their perceptions of individual success. Our tested models strongly suggest that this is true for males, females, adolescents and older adults. Our findings strongly suggest that mental health professionals should seek to strengthen families as they attempt to improve the psychological wellbeing of family members. Furthermore, greater family strength requires greater commitment to the family unit from all its members as well as greater mutual trust as they seek to overcome problems. These findings provide support to the hypothesis that psychosocial factors precede and significantly influence psychological dynamics. Other researchers are encouraged to study the same phenomena while relying on ex post facto longitudinal or experimental designs.

\section{References}

Baumrind, D. (1989). Rearing competent children. En W. Damon (Ed.), Child development today and tomorrow (pp. 349-378). San Francisco, CA: Jossey-Bass.

Bermúdez, M., Álvarez, T., \& Sánchez, A. (2003). Análisis de la relación entre inteligencia emocional, estabilidad emocional y bienestar psicológico. Universitas Psychologica, 2(1), 27-32.

Blanco, A., \& Díaz, D. (2005). El bienestar social: su concepto y medición. Psicothema, 17, 582-589.

Cronbach, L. J., \& Shavelson, R. J. (2004). My current thoughts on coefficient alpha and successor procedures. Educational and Psychological Measurement, 64, 91-418. http:// dx.doi:10.1177/0013164404266386

Cummins, R. A., Eckersley, R., Pallant, J., vanVugt, J., \& Misajon, R. (2003). Developing a national index of subjective wellbeing: The Australian unity wellbeing index. Social Indicators Research, 64(2), 159-190. http://dx.doi. org/10.1023/A:.1024704320683 
Díaz, D., Blanco, A., \& Durán, M. (2011). La estructura del bienestar: el encuentro empírico de tres tradiciones. Revista de Psicología Social, 26, 357-372. http://dx.doi. org/10.1174/021347411797361266

Díaz, D., Rodríguez, R., Blanco, A., Moreno, B., Gallardo, I., Valle, C., \& van-Dierendonck, D. (2006). Adaptación española de las escalas de bienestar psicológico de Ryff. Psichothema, 18, 572-577.

Díaz-Guerrero, R. (1982). Psicología del mexicano. México, DF: Trillas.

Díaz-Guerrero, R. (2003). Bajo las garras de la cultura. Psicología del mexicano 2. México, DF: Trillas.

Diener, E., Emmons, R. A., Larsen, R. J., \& Griffin, S. (1985). The satisfaction with life scale. Journal of Personality Assessment, 49(1), 71-75. http://dx.doi.org/10.1207/s15327752jpa4901_13

Duke, M., Lazarus, A., \& Fivush, R. (2008). Knowledge of family history as a clinically useful index of psychological well-being and prognosis: A brief report. Psychotherapy: Theory, Research, Practice, Training, 45, 268-272. http://dx.doi.org/10.1037/00333204.45.2.268

García, C. H., \& Corral, V. (2010). La identidad social y el locus de control interno en habitantes pobres del sur de Nuevo León, México. Revista de Psicología Social, 25(2), 231-239. http://dx.doi.org/10.1174/021347410791063750

Gracia, E., \& Musitu, G. (2000). Psicología social de la familia. Barcelona: Paidós.

Holtzman, W. H., Díaz-Guerrero, R., \& Swartz, J. D. (1975). El desarrollo de la personalidad en dos culturas. México, DF: Trillas.

Kantor, J. R. (1959). Interbehavioral psychology: A sample of scientific system construction. En Interbehavioral psychology and the logic of science (2nd, rev. ed.) (pp. 20-30). Bloomington, IN: Principia Press. http://dx.doi. org/10.1037/13165-002

Kantor, J. R., \& Smith, N. W. (1975). The science of psychology: An interbehavioral survey. Chicago, IL: Principia Press.

Keyes, C. L. M. (1998). Social well-being. Social Psychology Quarterly, 61, 121-140. http:// dx.doi.org/10.2307/2787065
Kim, K. H. (2005). The relation among fit indexes, power, and sample size in structural equation modeling. Structural Equation Modeling, 12, 368-390. http://dx.doi.org/10.1207/ s15328007sem1203_2

Kline, R. B. (2010). Principles and practice of structural equation modeling (3rd ed.). New York: The Guilford Press.

Lamers, S. M. A., Westerhof, G. J., Bohlmeijer, E. T., ten Klooster, P. M., \& Keyes, C. L. M. (2011). Evaluating the psychometric properties of the Mental Health Continuum-Short Form (MHC-SF). Journal of Clinical Psychology, 67, 99-110. http://dx.doi.org/10.1002/ jclp.20741

La Rosa, J. (1986) Escala de locus de control y autoconcepto: construcción y validación. Tesis Doctorado. México, DF: Universidad Nacional Autónoma de México.

La Rosa, J. (1988). Locus de control: una escala multidimensional. Revista de Psicología Social y Personalidad, 4(2), 43-64.

Leary, C., Kelley, M., Morrow, J., \& Mikulka, P. (2008). Parental use of physical punishment as related to family environment, psychological well-being, and personality in undergraduates. Journal of Family Violence, 23, 1-7. http://dx.doi.org/10.1007/s10896-0079124-9

McCubbin, M. A., McCubbin, H. I., \& Thompson, A. I. (1991). Family Hardiness Index. Madison, WI: University of Wisconsin.

McCubbin, M. A., McCubbin, I. H., \& Thompson, A. I. (1994). Family hardiness index. En J. Fischer \& K Corcoran (Eds), Measures for clinical practice: A sourcebook (2nd Ed.) (vol. 1, pp. 286-288). New York: Free Press.

Mirowsky, J., \& Ross, C. (2012). Social causes of psychological distress. New Brunswick: Aldine

Montalvo, J. (2009). Terapia familiar breve. México, DF: Trillas.

Moral, J., González, M., \& Ortega, M. E. (2009). Identidad y percepción del ambiente político en Monterrey. Enfoque psicosocial de la elección de 2006. Polis, 5(2), 79-119.

Müller, U., Sokol, B., \& Overton, W. F. (1999). Developmental sequences in class reason- 
ing and propositional reasoning. Journal of Experimental Child Psychology, 74, 69-106. http://dx.doi.org/10.1006/jecp.1999.2510

Omar, A., Uribe, H., Ferreira, C., Assmar, E., Terrones, A., \& Galaz, M. (2007). Colectivismo, justicia y ciudadanía organizacional en empresas argentinas, mexicanas y brasileras. Revista Mexicana de Psicología, 24(1), 101-116.

Orthner, D., Jones-Sanpei, H., \& Williamson, S. (2004). The resilience and strengths of low-income families. Family Relations, 53(2), 159-167. http://dx.doi.org/10.1111/j.00222445.2004.00006.x

Palomar, J. (2004). Poverty and subjective well-being in Mexico. Social Indicators Research, 68(1), 1-33. http://dx.doi.org/10.1023/ B:SOCl.0000025567.04153.46

Palomar, J., \& Cienfuegos, Y. (2007). Pobreza y apoyo social: un estudio comparativo en tres niveles socioeconómicos. Revista Interamericana de Psicología, 41(2), 177-188.

Pettit, G., Bates, J., \& Dodge, K. (1997). Supportive parenting, ecological context, and children's adjustment: A seven year longitudinal study. Child Development, 68, 908-923. http://dx.doi.org/10.2307/1132041

Rochat, P. (2009). Others in mind: Social origins of self-consciousness. Cambridge: Cambridge University Press. http://dx.doi.org/10.1017/ CBO9780511812484

Sánchez, J. (1998). Escala de bienestar psicológico (EBP). Madrid: TEA.

Sociedad Mexicana de Psicología (2007). Código ético del psicólogo (4ta. edición) México, DF: Trillas.

Su, Y., \& Li, Y. (2002). Children's well-being during parents' marital disruption process: A pooled time-series analysis. Journal of Marriage and Family, 64, 472-488. http://dx.doi. org/10.1111/j.1741-3737.2002.00472.x

Treviño, F. A., \& García, C. H. (2012). El efecto de la resistencia psicológica y el apoyo social sobre el bienestar subjetivo de empleados y desempleados. Revista Interamericana de Psicología Ocupacional, 31(1), 5-11.

Triandis, H. (2001). Individualism-collectivism and personality. Journal of Personality, 69(6), 907-924. http://dx.doi.org/10.1111/14676494.696169
Vargas, J. G. (2007). La culturocracia organizacional en México. Málaga, España: Grupo Eumed.Net.

World Health Organization (2004). Promoting mental health: Concepts, emerging evidence practice. Geneva: Author.

Zubieta, E., Muratori, M., \& Fernández, O. (2012). Bienestar subjetivo y psicosocial: explorando diferencias de género. Salud \& Sociedad, 3(1), 66-76.

Self-references for authors: 2

Self-references for JBHSI: 0 